\title{
Personal Impressions Of the Medical Services In the Present War
}

\section{Commentary}

\section{SG Mellor}

Philip Mitchiner was a Surgeon to St Thomas's Hospital and had a highly successful parallel military career, starting with the OTC at the tender age of sixteen in 1904, subsequently with the TA and latterly as DDMS Northern Command in the rank of Major General. It was during this appointment that he wrote this paper with nearly forty years of experience looking at medical support to the Armed Forces in all its guises. His first exposure to war wounds was in Serbia in 1920-21 for the Relief Fund Organisation (trouble in the Balkans never goes away).

Philip Mitchiner's contemporaries are clear that he was first and foremost a doctor: he gives the impression of a man with a great sense of humour who could extract the best from all those with whom he came in contact. He was well known as an excellent committee man who could put his point forcefully and succinctly and be successful because of his ability to provide a simple solution where everyone else found problems. This clearly comes across in this paper as he demonstrates his ability to see all aspects of provision of medical services to the Armed Forces. He understands the importance of the role of the Regimental Medical Officer in all its facets, ranging from the importance of hygiene to the more spiritual aspects of the soldier's welfare. Later on in the paper he comments on the importance of good footwear and footcare and general treatment of common medical conditions. It is hardly surprising that he advocated the importance of a good knowledge of First Aid by soldiers, but he makes clear that the training should be disseminated within the unit by officers and NCOs so that all ranks have ownership of the problem. He also makes the point that drills should be simple and effective to achieve the best results, concentrating, for example, on the ability to apply pressure bandages in confined spaces, under difficult conditions, and with speed and accuracy. His comments about evacuation of casualties from the battlefield and their management remain as fresh today as they were then. $\mathrm{He}$ is clear about the need for resuscitation with blood and plasma prior to surgery, but is concerned by over enthusiastic use of blood and plasma at Aid Posts and Dressing Stations. He was clearly an advocate of the 'scoop and run' philosophy and it may be that he saw early on the advantages of hypotensive resuscitation!
Mitchiner's surgical reputation also appeared to be founded on his great ability to see simple solutions where others only saw problems. This clarity of thought made him a respected teacher and a sought after opinion. His contemporaries did not see him as a great technical surgeon and he was a notorious instrument thrower in the operating theatre: his main claim to surgical fame arose from his experience and ability to treat damaged and infected soft tissue and bone in the pre-antibiotic era. In this paper he clearly describes the steps in treating wounds of war, which were painfully relearned in WW1 and may have been ignored in some quarters in the early part of WW2. He notes the lack of need to deal with multiple puncture wounds such as those inflicted by small fragments thrown up by explosions, and this observation has been confirmed experimentally by recent work. He writes of wound excision in the first few hours of wounding, but on the whole condemns primary suture unless it can be achieved within a few hours of wounding. He stresses the vital importance of debridement, as described by Ambroise Pare. This is the 'unbridling' or wide laying open of wounds so that local oedema caused by the inflammatory response to wounding does not cause further damage and lead to infection and so that the wound can drain freely. He makes an interesting point about delayed union of fractures, pointing out that this occurred when fractures are over distracted on traction. He was also very interested in the management of burns and advocated the tanning of burns to ensure asepsis and thereby uneventful healing. As a matter of interest, the aim of tanning was to produce a rigid eschar rapidly, under which healthy granulation tissue could develop. Unfortunately, such a procedure was far more likely to act as a nidus for infection, and often proved disastrous in extensive burns. $\mathrm{He}$ was an advocate of the need for colloid resuscitation of the patient with larger burns, and is dismissive of resuscitation with crystalloid.

Whatever one may think about Mitchiner's views on management of the diverse range of conditions he describes, it is his ability to grasp the nub of all problems whether surgical, medical or of a more general nature. $\mathrm{He}$ displays the commonsense and humanity in his approach to all these areas which I am sure we would all wish to see in our medical administrators. 
RAMC Journal 1943 Vol LXXX No. 2 51-57

\section{Original Communications}

\section{PERSONAL IMPRESSIONS OF THE MEDICAL SERVICES IN THE PRESENT WAR}

By Major-General Philip H Mitchiner CBE TD MD MS FRCS KHS

I have been able during my wanderings in the present war to see much of the work of the medical services, not only of the Army, but of the Navy, Air Force and Civil Organizations (E.M.S.). Generally speaking, I have been impressed greatly by the quiet efficiency of their organization and the understanding and co-operation which exists especially between the higher ranks of all Services. I may, however, be permitted to remark that cooperation is not always so complete, even in the same Service, between the regimental, area and station medical officers themselves and their civil colleagues, which I think is all too often due to lack of personal contact, failure to achieve which is due in many cases to shyness in visiting or an erroneous fear that such a procedure may not be a Service custom or even derogatory to personal dignity! Such co-operation is essential to the efficient running of medical services and can be possible only where personal knowledge of one's colleagues and their difficulties exists.

In many cases also, criticism, which is always helpful if of a constructive nature, is unhelpful because it is bitter and destructive and - alas - all too often given to laymen and patients. This is a matter where thoughtless criticism has done very much to undermine the good standing of the medical services throughout the whole country and is one to which too much attention cannot be paid by my many colleagues who must learn - often a very bitter lesson - that there are other medical men who by different methods can show themselves just as good doctors.

Specialism. - I have been very much struck in all walks of medical life by the great number of specialists, all too frequently selfstyled, who are there to diagnose and treat diseases, and the great scarcity of doctors to treat patients! It must be remembered that the first task of the medical service is to keep men fit and not merely tinker up diseased bodies; to do this a doctor must exercise his knowledge of the world, or people and his common sense as well as his professional skill. He must co-operate closely with the regimental officer in preventing boredom, ensuring mental and physical alertness as well as supervising diet, personal habits and hygiene of the many men in his unit whose personalities he must study carefully. It will be seen therefore that he must be first a doctor and has then scope for all and every speciality which exists. All these constitute his endless and all-absorbing duty, which is very much more than routine sick parade, inoculations and the completion of returns for statistical purposes.
Medical Services in Battle. - From what little I have seen of active service in the present war I am inclined to think that there is really no place for the medical services in the chaos of modern battle and that it would be well for military efficiency if the medical services were withdrawn from the battle area until a lull has occurred, when they could be sent forward to collect casualties and return them to those units where surgery can be performed as near the battle area as possible. To this end mobile surgical teams and dental units have been designed and should form a valuable adjunct to the re-organized medical services working in the field dressing stations or, in exceptional circumstances, even forward at the advanced dressing station of a field ambulance. In order to ensure their transport and the evacuation of casualties with reasonable security it will surely be necessary to provide armour for ambulances and vehicles of mobile teams, especially those which accompany armoured divisions. In this respect it has struck me very forcibly that in such units one or two light ambulance cars could be attached to the headquarters of each tank battalion and used to pick up casualties as lulls occur locally with the object of evacuating them back to Brigade headquarters and the field ambulance, in which region I venture to think the R.M.O.s of the various tank battalions could be concentrated with advantage during the battle.

First Aid. - As a corollary of the foregoing remarks it is obvious that every officer, man and auxilliary in the entire Army must have an elementary knowledge of first aid so as to be able to help himself and his immediate companions in the event of sustaining wounds in these grim and extensive battles, during which no immediate medical aid is feasible. For this reason it is essential that everyone throughout the Service should be taught elementary first aid. For this purpose five lecture-demonstrations-on Haemorrhage, Shock, Burns, Blast Injuries and Fractures - should be given to all personnel. It is best that the medical officer should instruct officers and N.C.O.s and allow them to transmit the instruction to the other ranks of their unit. It is, however, essential that the medical officer should oversee the practice of the first aid teaching which must be carried out regularly at monthly intervals in order that all men may understand the simple methods which must be taught. In regard to the teaching of first aid it is essential that such instruction should be simply-worded and entail only one method of treating each 
condition suitable to the conditions likely to prevail on active service so as to avoid muddling the first aid worker. Speed, not perfection, must be aimed at in applying dressings and the personnel taught to do their first aid in the dark by the light of an electric torch or the flickering glow of firelight and under cramped conditions such as exist in armoured fighting vehicles.

Remember that the tourniquet, in other than medical hands, is all too often used unnecessarily and causes the loss of more limbs than the saving of lives, though this is not the opinion in some R.A.F. circles where each member of a bomber crew carries a tourniquet.

One cannot help being struck with admiration by the ingenuity of the many methods employed to remove wounded from aircraft, tanks and naval vessels and I think that more demonstrations should be given to get these methods wider publicity.

Triage. - It is essential to have an experienced doctor, with quick decision and good surgical knowledge, to sort the casualties on arrival at aid posts and dressing stations. Thereby lives are saved. Many of the apparently trivial wounds have penetrated and need operation; the slightly shocked have an internal haemorrhage; two or more injuries co-exist of which one may not be obvious; and the need for resuscitation may be great and urgent in an apparently placid casualty.

Shock. - What constitutes shock? Its clinical phenomena are seen almost as severely in the mentally upset and shaken as in those who have severe haemorrhage or extensive burns. Yet in the latter types there is accompanying restlessness and air hunger which is absent in the former type where, however, the more mentally intellectual the patient the greater tendency to restlessness and mental irritability. Incidentally, this type of patient is very liable to become a chronic alcoholic, not of the honest type, but a "nipper" and a keeper of a bottle under the bed. It behoves the doctor, therefore, to keep an eye and a tight hand on all the good fellows of this type, where much can be done by understanding and a word in season. It is just possible that all these conditions are due to tissue dehydration induced by mental overaction and free sweating and aggravated by loss of blood and other body fluids? If so, then we should face battle with a body full of fluid taken as drink and try to get more drink during and after it; a point well known to the Army and in First Aid work, as here the provision of hot drinks is one of the chief concerns of all forward and First Aid units.

Never forget resuscitation is a necessary preliminary to treatment. I cannot help feeling there is too great a tendency to resort to transfusion unnecessarily, with resultant waste of good blood, plasma or serum with not more, and even less, benefit to the patient than would be derived from the simple and easier methods which can be administered anywhere by all First Aid workers. Certainly transfusions should not be given in the streets and in the average regimental aid posts - not to me at any rate.

Wounds. - Bomb wounds as I have seen them are of two main classes : (a) Small multiple superficial wounds, often associated with multiple punctures from broken glass, involving large areas of the body, and being far too widespread to allow for excision (without flaying the patient - a shock producing torture!) and best treated, I think, after adequate soap and water cleaning, not with a brush, by painting with 1 percent aqueous gentian violet or powdering with sulphonamide powder if around the eyes. But be sure that no one of the small and apparently superficial punctures has penetrated deeply - and no cursory examination will ensure this. I have seen meningitis, a perforated portal vein and internal haemorrhage complicating such multiple "superficial" wounds dressed in a First Aid Post and ordered home! (b) Large lacerated wounds which may eviscerate, avulse limbs or remove the lower jaw and portions of the face. All such wounds are complicated more or less by the effects of blast, a puckish element of which, as of the Irishman, one may say "it is impossible to prognosticate his reaction and it is doubtful if he can do so himself." Broadly, the effect of blast is concussion which may cause multiple haemorrhages in any of many viscera; and the great secret of successful treatment is to have the patient quiet and undisturbed. One cannot leave such a case in the open in the street or on the field of battle; but dope the patient well with morphia - move him back such a distance at one move that he can be retained undisturbed for at least fourteen days. Many short moves spell death and disaster in blast cases.

Bullet wounds present no special features other than are well known, nor do the many closed and open fractures which occur, the latter often as a complication of accidents and wounds.

In regard to delayed union which is so generally noted in fractures during the present war I feel convinced that this is due to over-manipulation and hyperextension in correcting the fracture and is to be attributed therefore to orthopaedic interference. It is a noteworthy fact that in certain clinics which I have visited where over-traction is carefully not employed delay in union is not seen.

It is for consideration therefore whether too perfect an anatomical position, obtained at the loss of man hours, is economically sound.

Wound Treatment. - Wound treatment calls perhaps for some comment. Only if excision can be performed in the first few hours can primary union be hoped for and then it seldom occurs. Under conditions of 
modern war and aerial bombardment it is not often possible to get the patient to the operating theatre under twelve hours from receipt of the wound and it may be very much longer. Under these conditions infection is bound to occur and excision must give place to débridement, removal of obviously dead or damaged tissues, and the provision of an adequate counter-opening for drainage at the most dependent part of the wound. In this respect remember "the most dependent part" must be applied to the position in which the patient will be nursed in bed and not as he lies on the operating table. Much good work is wasted and second operations rendered necessary by forgetfulness of this simple fact in the rush of casualty surgery.

As to whether or not sulphonamides should be powdered into the wound after surgical cleaning by excision or débridement (certainly never without), is, I think, a matter for judgment and should be determined largely by whether sepsis is likely to occur. So that as a general rule it is unnecessary if excision is early and thorough. Care must be taken not to use more than 10 grammes or toxic effects may occur. Personally, I am not convinced as to the benefits of local wound application over administration by mouth if it can be ensured that this can be started should sepsis manifest itself. But it is obvious that, in an unconscious patient or one being moved within a few hours of operation, an unwise proceeding if it can be anyway avoided, local application of sulphonamides in the would has much to recommend it.

It is probably a wise rule not to suture any wound after excision, certainly never after débridement, and never if there is any suspicion of tension on either deep or superficial sutures. An exception occurs in facial wounds where skin should be sutured always to mucous membrane and the case conveyed to a maxillo-facial clinic with the minimum of delay.

Dressings. - Lacerated wounds and open fractures do best, and the patient is far more comfortable, if the part is encased and immobilized in plaster of paris after the method popularly associated with Trueta, but practiced by some French (and even British!) surgeons with success in the late war. But if the patient is travelling in an ambulance or being moved from the surgeon's personal supervision within four days from the operation, the plaster must be bivalved, for if sepsis occurs oedema may and does often lead to loss of limb and even life. There is no means in an ambulance of bivalving a plaster and once a patient is committed to an ambulance, or indeed any transport under war conditions, only God knows when he will leave it. Incidentally, I wonder how many of my readers have ever ridden in an ambulance and realize what an uncomfortable and shock-producing journey it is, even under the best conditions. Never commit a really ill patient to an ambulance under war conditions unless circumstances render it unavoidable.

Burns. - At the outbreak of the present war it had, I think, become generally accepted that some form of tanning constituted the ideal treatment for burns. Since then we have seen a return to chaos and the advocacy of almost all forms of obsolete and long-forgotten treatments (except cowpats) and several new ones of various values. Why this complete volte-face? The reason, I think, lies in the fact that under war conditions the early and thorough cleaning of and around the burnt area, equally essential to ensure asepsis in healing as early and thorough wound toilet, is impossible or next to impossible to attain, so that, as with most wounds, all burns must be expected to go septic and will do so.

If, then, a rigid tan is applied oedema under it from sepsis and inflammatory reaction, as under a plaster of paris around a limb, will probably cause pressure gangrene of tissues not to mention great pain. Hence the swing back to the use of older and, to my mind, less satisfactory methods of treatment with the added reason that the plastic specialists call for a soft scar on which to exercise their art. I have yet to see statistics of the number of burnt patients who perish before their soft scars come to the plastic surgeon. Be this as it may I am convinced that, as a first aid measure, immediate tanning, either by tannafax, gentian violet, brilliant green or triple dye (these latter not easily portable in the field except in "jelly" form) or even tea, is the only sure way of easing pain and saving life in many cases of severe burns under war conditions. Patients so treated are saved shock and arrive far fitter than those submitted to other first aid dressings. Of course cleaning must be carried out in hospital; but whatever method has been used sepsis is to be expected, hence the rationale of hyperchlorite in silken sacs so ably advocated by Bunyan. Personally, I should prefer using a method producing a non-rigid crust if I thought sepsis would occur to any great degree.

Sulphonamides are an excellent dressing for face and perineal burns and may be given with advantage by mouth as a prophylactic to sepsis in all severe burns from the commencement of treatment.

Shock always needs treatment and serum or plasma is better than whole blood while saline is to be avoided in burned patients, being very prone to cause lung oedema. Drip transfusion is of value after the first pint of fluid and can in severe cases be continued with advantage for a day or two as necessary. Should pain occur under any coagulum it is an indication for its instant removal, as it means pressure oedema, usually from incipient sepsis. 
Painful Heels. - Painful heels cause much trouble, as do other foot troubles, in the field army, due partly I think to the fact that troops seldom walk; so the care of feet and foot gear tends to be neglected. Much can be done with care and attention to systematic cleanliness of feet and regular washing and proper darning of socks and the softening of boots.

\section{Medical Conditions}

It may be considered impertinent that I, a surgeon, should comment on medical conditions but there are one or two facts about these which I think call for comment.

Respiratory disease, in spite of overcrowding, unavoidable under certain conditions for short periods, have been uncommon and can be greatly lessened either by spraying before billets are occupied each evening or by suspending trays of bleach above the heads of the inhabitants and stirring it up once a day.

Skin diseases, apart from scabies which is a serious problem, do not call for comment.

Scabies has many cures with vocal and ardent advocates, but I feel convinced that thorough hot bathing, entailing a real scrub with soap and water together with a synchronous change into clean underclothes, is the true solution, combined with an effective carrying out of the provisions of the Scabies Order at the patient's home. From my observations I do not think disinfection of bedding necessary but where no pants or short pants are worn disinfestation of trousers should be carried out. Don't forget the A.T.S. get scabies.

Digestive troubles are most marked in the first weeks of service and tend to disappear with acclimatization to diet and as the recruit becomes regular in bowel habits and accustomed to fitting them with Service routine. The Army Catering Corps is to be congratulated on its efforts to improve the feeding and cooking in the Army but there is still a tendency to serve too greasy dishes in many units.

V.D. has been surprisingly low in incidence and mild in type. I have been struck with the efficacy of sulphonamide treatment and the very small proportion of relapses following its use and also by the extremely toxic condition of the unfortunate patients whilst under treatment.

In regard to the treatment of syphilis, it is, I think, a pity that more use is not made of mepharside, which appears equally effective and far less toxic than the arsenical compounds used in the Army.

\section{Conclusion}

There are doubtless many other conditions, surgical, medical, pathological, pyschical and even gynaecological, upon which I might have commented and which can be seen at the profitable clinical meetings of the many Service medical societies, some of which it has been my privilege and profit to attend; but these are in the ordinary interesting routine of our professional life and call for no special comment under war conditions.

Moreover, I have not dwelt on the interest of visits to units where normal men and women delight one with hospitality and discourse and intrigue one with the diversity of their natures. Surely there is never one dull minute in the life of a Service medical officer!

Finally I must thank all my many colleagues in many places and Services who have so courteously received, entertained and tolerated me. Doubtless many of them will entirely disagree with my conclusions - I hope they will not hesitate to say so and record their own. 